\title{
Access to Liver Transplantation and Patient Survival among Asian Populations: Pre-Share 35 vs. Post-Share 35
}

\section{Yefei Zhang*}

Department of Biostatistics, School of Public Health, University of Texas Health Science Center, Houston, TX, USA

\begin{abstract}
Background: Studies addressing ethnic disparities and trends in liver transplantation for Asian population is scant The objective of this study was to examine the impact of Share 35 policy on Asian patients' access to liver transplantation and outcomes since its implementation in June, 2013.
\end{abstract}

Methods: A total of 11,910 adult white and Asian patients who were registered for deceased donor liver transplantation between 2012 and 2015 were identified from UNOS database. Logistic regression and proportional hazards models with adjustment for demographic, clinical, and geographic factors were used to model the access to liver transplantation and patient survival. Stratification on pre- and post-Share 35 periods was performed to compare the first 18 months of Share 35 policy to an equivalent time period.

Results: Comparison of the pre- and post-Share 35 periods showed significantly decreased time on waiting list and higher proportions of patients receiving liver transplantation for Asian patients. Asians shared similar transplant rates as whites (OR: $1.15,95 \% \mathrm{Cl}: 0.80-1.67)$ but experienced significantly longer waiting time (HR: $0.56,95 \% \mathrm{Cl}: 0.34-0.92)$ before they received liver transplantation after Share 35 policy took effect. No significantly post-transplantation survival difference has been observed between Asians and whites at the one and half year outcome.

Conclusion: Asian patients are still at greater risk of disparities in access to liver transplantation under the Share 35 policy. Future researches with long-term follow-up time are recommended to continuously evaluate the effectiveness of the new policy.

Keywords: Asian; Disparity; Liver transplantation; Share 35 policy; United Network for Organ Sharing

\section{Introduction}

Based on the US Census Bureau Population Projections, it was estimated that minority populations would grow by $2 \%$ per year over the next two decades, whereas Asian population will make up approximately $11.7 \%$ of the US population by 2060 [1]. Previously, studies addressing ethnic disparities and trends in liver transplantation have traditionally focused on African Americans and Hispanics and the information for Asian population is scant [2-5] One preliminary study using national cancer surveillance data from 1998-2002 found that white patients were 2.56 times more likely to receive a liver transplantation than Asian and Pacific Islanders with hepatocellular carcinoma (HCC) in the pre-Model for End-Stage Liver Disease (MELD) era, but not in the post-MELD era from 2003-2005 [2]. Another study using the United Network for Organ Sharing (UNOS) database for all adult Asian liver transplantation recipients from 1998-2007 indicated that Asian ethnicity had a significant survival advantage in comparison to nonAsian [3].

On June 18, 2013, the Share 35 policy was implemented by the UNOS, which dramatically changed the allocation of donor livers. It mandates that regional sharing of livers for patients with a MELD score of $\geq 35$ is prioritized over local sharing to patients with a MELD score of $<35$. The intention of the policy was to reduce the waiting list mortality. Recent preliminary analyses have reported decreased mortality rates under Share 35 policy, but did not observe any significantly difference in the post-transplantation survival [6-9]. However, no study has ever investigated among Asian populations.

Therefore, the purpose of this study was to assess the access to liver transplantation and transplantation outcomes among Asian populations under the Share 35 policy using the recent UNOS waiting list and liver database comparing the first 18 months of Share 35 policy to an equivalent time period before, while accounting for geographical and other factors.

\section{Patients and Methods}

\section{Data source}

UNOS is a private, non-profit organization that manages the nation's organ transplant system under contract with the federal government [10]. Detailed descriptions of the UNOS registry have been published elsewhere [11]. Briefly, data were collected by each transplant center and transmitted to UNOS. The registry records and documents any change in standard demographic, clinical, and laboratory information available at the time of listing, during transplantation, and post-transplantation, as well as information on the donors. The Standard Transplant Analysis and Research (STAR) file of the UNOS database contains one record per transplantation event.

The committee for the Protection of Human Subjects at the University of Texas Health Science Center at Houston approved this study.

*Corresponding author: Yefei Zhang Department of Biostatistics, Schoo of Public Health, University of Texas Health Science Center at Houston, 1200 Pressler Street, RAS-E803f, Houston, TX 77030, USA, Tel: 1-626-375-1906; E-mail: Yefei.Zhang@uth.tmc.edu

Received January 22, 2017; Accepted February 08, 2017; Published February 15, 2017

Citation: Zhang Y (2017) Access to Liver Transplantation and Patient Survival among Asian Populations: Pre-Share 35 vs. Post-Share 35. Health Care Current Reviews 5: 187. doi: 10.4172/2375-4273.1000187

Copyright: (C) 2017 Zhang Y. This is an open-access article distributed under the terms of the Creative Commons Attribution License, which permits unrestricted use, distribution, and reproduction in any medium, provided the original author and source are credited. 
Citation: Zhang Y (2017) Access to Liver Transplantation and Patient Survival among Asian Populations: Pre-Share 35 vs. Post-Share 35 . Health Care Current Reviews 5: 187. doi: 10.4172/2375-4273.1000187

Page 2 of 5

\section{Study population}

A total of 15,789 candidates with end stage liver disease (ESLD), 18 years of age and older, with an initial data of registration for deceased donor liver transplantation between January $1^{\text {st }}, 2012$ and March $31^{\text {st }}$, 2015 were identified from the STAR wait list and liver file of the UNOS database. Only candidates with race/ethnicity defined as non-Hispanic white and Asian were selected $(n=11,919)$. Candidates were then excluded for the following reasons: missing body mass index (BMI) $(\mathrm{n}=3)$, missing diagnosis $(\mathrm{n}=5)$ and unknown MELD score at listing $(n=1)$. After all exclusions, a total of 11,910 patients were available for analysis.

\section{Study variables}

The exposure variable of primary interest was race and ethnicity as reported in UNOS records, classified as non-Hispanic white (severing as the reference group) and Asian. Other patient demographic and clinical characteristics included age at listing, gender, BMI, diagnosis, MELD score at listing, time on waiting list, waiting list outcomes, presence of HCC, presence of hepatitis $\mathrm{C}$ virus (HCV), presence of hepatitis $B$ virus (HBV), organ location and history of diabetes. The primary outcomes for all waiting list candidates included 1): the receipt of liver transplantation, and 2) the total time on the waiting list. Followup began for patients when they were initially added to the waiting list. They were then followed until the earliest of liver transplantation, death, the granting of a MELD exception score or the end of the study. Patients received a liver transplantation, alive, or lost to follow-up were censored at the date of transplantation or last follow-up. Among those who received liver transplantation, another primary outcome was posttransplantation patient survival. Patient survival in years was calculated from the date of liver transplantation to the date of death or the date of the last follow-up. Recipients alive or lost to follow-up were censored at the date of last follow-up.

\begin{tabular}{|c|c|c|c|c|}
\hline & \multicolumn{2}{|c|}{$\begin{array}{c}\text { Pre-Share } 35 \\
(n=6,112)\end{array}$} & \multicolumn{2}{|c|}{$\begin{array}{l}\text { Post-Share } 35 \\
(n=5,798)\end{array}$} \\
\hline & $\begin{array}{c}\text { White } \\
(n=5,772)\end{array}$ & $\begin{array}{c}\text { Asian } \\
(n=340)\end{array}$ & $\begin{array}{c}\text { White } \\
(n=5,486)\end{array}$ & $\begin{array}{c}\text { Asian } \\
(n=312)\end{array}$ \\
\hline Age at listing (years), mean (SD) & $55.7(9.9)$ & $55.1(11.5)$ & $55.6(10.5)$ & $54.8(10.7)$ \\
\hline \multicolumn{5}{|l|}{ Gender, $\mathbf{n}(\%)$} \\
\hline Male & $3,913(67.8)$ & $225(66.2)$ & $3,694(67.3)$ & $203(65.1)$ \\
\hline Female & $1,859(32.2)$ & $115(33.8)$ & $1,792(32.7)$ & $109(34.9)$ \\
\hline BMI, mean (SD) & $28.5(5.6)$ & $24.9(4.1)$ & $28.6(5.9)$ & $25.3(4.9)$ \\
\hline Time on waiting list (days), median (IQR) & $92(21-246)$ & $126(26-350)$ & $53(11-146)$ & $53.5(7-188)$ \\
\hline \multicolumn{5}{|l|}{ Waiting list outcomes, $n(\%)$} \\
\hline Transplanted & $4,685(81.2)$ & $280(82.4)$ & $4,673(85.2)$ & $272(87.2)$ \\
\hline Still waiting & $235(4.1)$ & $21(6.2)$ & $166(3.0)$ & $17(5.5)$ \\
\hline Temporarily too sick & $633(11.0)$ & $28(8.2)$ & $489(8.9)$ & $14(4.5)$ \\
\hline Insurance issues & $89(1.5)$ & $1(0.3)$ & $70(1.3)$ & $3(1.0)$ \\
\hline Medical non-compliance & $53(0.9)$ & $1(0.3)$ & $22(0.4)$ & - \\
\hline Candidate withdrawn & $73(1.3)$ & $9(2.7)$ & $63(1.2)$ & $5(1.6)$ \\
\hline Candidate cannot be contacted & $4(0.1)$ & - & $3(0.1)$ & $1(0.3)$ \\
\hline \multicolumn{5}{|l|}{ MELD at listing, $n(\%)$} \\
\hline$<35$ & $5,288(91.6)$ & $307(90.3)$ & $4,739(86.4)$ & $244(78.2)$ \\
\hline$\geq 35$ & $484(8.4)$ & $33(9.7)$ & $747(13.6)$ & $68(21.8)$ \\
\hline \multicolumn{5}{|l|}{ Presence of HCC, $n(\%)$} \\
\hline No & $4,358(75.5)$ & $191(56.2)$ & $4,340(79.1)$ & $208(66.7)$ \\
\hline Yes & $1,414(24.5)$ & $149(43.8)$ & $1,146(20.9)$ & $104(33.3)$ \\
\hline \multicolumn{5}{|l|}{ Presence of HCV, $n(\%)$} \\
\hline No & $3,263(56.5)$ & $245(72.1)$ & $3,350(61.1)$ & $234(75.0)$ \\
\hline Yes & $2,344(40.6)$ & $87(25.6)$ & $1,931(35.2)$ & $68(21.8)$ \\
\hline Unknown & $165(2.9)$ & $8(2.4)$ & $205(3.7)$ & $10(3.2)$ \\
\hline \multicolumn{5}{|l|}{ Presence of HBV, $n(\%)$} \\
\hline No & $4,511(78.2)$ & $136(40.0)$ & $4,437(80.9)$ & $117(37.5)$ \\
\hline Yes & $935(16.2)$ & $186(54.7)$ & $801(14.6)$ & $182(58.3)$ \\
\hline Unknown & $326(5.6)$ & $18(5.3)$ & $248(4.5)$ & $13(4.2)$ \\
\hline \multicolumn{5}{|l|}{ Organ location, n (\%) } \\
\hline Local & $4,376(75.8)$ & $252(74.1)$ & $3,609(6.8)$ & $182(58.3)$ \\
\hline Regional & $1,222(21.2)$ & $77(22.7)$ & $1,654(30.2)$ & $121(38.8)$ \\
\hline National & $174(3.0)$ & $11(3.2)$ & $223(4.1)$ & $9(2.9)$ \\
\hline \multicolumn{5}{|l|}{ History of diabetes, $\mathbf{n}(\%)$} \\
\hline No & $4,307(74.6)$ & $234(68.8)$ & $4,084(74.4)$ & $237(76.0)$ \\
\hline Yes & $1,437(24.9)$ & $106(31.2)$ & $1,394(25.4)$ & $75(24.0)$ \\
\hline Unknown & $28(0.5)$ & - & $8(0.2)$ & - \\
\hline
\end{tabular}

SD: Standard Deviation; IQR: Interquartile Range; BMI: Body Mass Index; MELD: Model for End-Stage Liver Disease; HCC: Hepatocellular Carcinoma; HCV: Hepatitis C Virus; HBV: Hepatitis B Virus

Table 1: Baseline demographic and clinical characteristics of waiting list candidates in the entire cohort by race: Pre-Share 35 vs. Post-Share 35 time periods, $2012-2015$. 


\section{Statistical analysis}

Chi-square tests and t-tests were used to compare the baseline demographics and clinical characteristics between the two racial groups as well as between pre-Share 35 and post-Share 35 periods. To incorporate the impact of geography and transplant center, marginal logistic regression models and Cox proportional hazards models were used to model the effects of Asian race on the receipt of liver transplantation, the total waiting time on the list, and posttransplantation survival. All other potential risk factors were included in the models. Stratifications between pre-Share 35 period and postShare 35 periods were also performed. All statistical analyses were performed with SAS version 9.4 (SAS Institute Inc., Cary, NC). P-values less than 0.05 were considered statistically significant.

\section{Results}

The baseline demographic and clinical characteristics of the 11,910 patients registered on waiting list were displayed in Table 1. Compared to the pre-Share 35 cohort, Asian and white subgroups in the postShare 35 cohort were similar with respect to the following factors: age at listing, gender, HCV status, HBV status and history of diabetes. The median time on waiting list decreased significantly from 126 days to 53.5 days for Asians and from 92 days to 53 days for whites. When it came to waiting list outcomes, both Asians (increased from $82.4 \%$ to $87.2 \%$ ) and whites (increased from $81.2 \%$ to $85.2 \%$ ) had higher proportions of patients receiving liver transplantation, while lower proportions of patients still waiting on the list or being too sick to receive transplantation. There were significantly more Asian patients with higher BMI, MELD score greater than 35 registered on the waiting list, HCC negative, and more regional organs after the implementation of the Share 35 policy.
Table 2 displayed the risk-adjusted odds ratios for liver transplant rates among patients registered on waiting list for both pre- and post-Share 35 periods. Asian candidates shared similar likelihood of receiving liver transplantation as compared to white candidates both in the pre-Share 35 era (OR: 1.04, 95\% CI: 0.77-1.41) and post-Share 35 era $(1.15,0.80-1.67)$.

The Cox proportional hazard regression results of the waiting time before the access to liver transplantation for both pre- and postShare 35 periods were presented in Table 3 . Asian patients had to wait approximately $50 \%$ longer on the waiting list before receiving liver transplantation compared to white patients (HR: 0.56, 95\% CI: 0.34 0.92 ) after the Share 35 policy.

We further investigated the post-transplantation survival for patients who were removed from waiting list and received liver transplantation and the Cox proportional hazard regression results were presented in Table 4 . No statistically significant difference in patient survival between Asian and white patients has been observed either in pre-Share $35(0.82,0.58-1.16)$ or in post-Share 35 era $(0.92$, $0.59-1.44)$ at the one and half year outcome.

\section{Discussion}

Overall, the study observed significantly decreased time on waiting list and higher proportion of patients receiving liver transplantation after the Share 35 policy. Asian patients had similar transplant rates and survival rates as their white counterparts, but experienced $50 \%$ longer waiting time before the receipt of liver transplantation. To the best of knowledge, this study was the first study to explore the access to liver transplantation and patient survival for Asian patients with ESLD after the Share 35 policy implemented in June 2013.

Apparently, for both Asian and white patients added to the UNOS

\begin{tabular}{|l|c|c|}
\hline & $\begin{array}{c}\text { Pre-Share 35 } \\
(\mathbf{n = 4 , 9 6 5 )}\end{array}$ & $\begin{array}{c}\text { Post-Share 35 } \\
(\mathbf{n = 5 , 7 9 8 )}\end{array}$ \\
\hline White & Odds Ratio (95\% Confidence Interval) & Odds Ratio (95\% Confidence Interval) \\
\hline Asian & 1.00 (reference) & $1.00($ reference) \\
\hline
\end{tabular}

"Odds ratios adjusted for age, gender, BMI, diagnosis, MELD score at listing, presence of HCC, presence of HCV, presence of HBV, organ location and history of diabetes BMI: Body Mass Index; MELD: Model for End-Stage Liver Disease; HCC: Hepatocellular Carcinoma; HCV: Hepatitis C Virus; HBV: Hepatitis B Virus

Table 2: Logistic regression results for the receipt of liver transplantation among patients registered on waiting list: Pre-Share 35 vs. Post-Share 35 time periods, $2012-2015$.

\begin{tabular}{|l|c|c|}
\hline & $\begin{array}{c}\text { Pre-Share 35 } \\
(\mathbf{n = 6 , 1 1 2 )}\end{array}$ & $\begin{array}{c}\text { Post-Share 35 } \\
(\mathbf{n = 5 , 7 9 8 )}\end{array}$ \\
\hline White & Hazard Ratio (95\% Confidence Interval) & Hazard Ratio (95\% Confidence Interval)* \\
\hline Asian & 1.00 (reference) & $1.00($ reference) \\
\hline
\end{tabular}

* Hazard ratios adjusted for age, gender, BMI, diagnosis, MELD score at listing, presence of HCC, presence of HCV, presence of HBV, organ location and history of diabetes BMI: Body Mass Index; MELD: Model for End-Stage Liver Disease; HCC: Hepatocellular Carcinoma; HCV: Hepatitis C Virus; HBV: Hepatitis B Virus

Table 3: Cox proportional hazard regression results for the waiting time before liver transplantation among patients registered on waiting list: Pre-Share 35 vs. Post-Share 35 time periods, 2012-2015.

\begin{tabular}{|l|c|c|}
\hline & $\begin{array}{c}\text { Pre-Share 35 } \\
(\mathbf{n = 4 , 9 6 5 )}\end{array}$ & $\begin{array}{c}\text { Post-Share 35 } \\
(\mathbf{n = 4 , 9 4 5 )}\end{array}$ \\
\hline White & Hazard Ratio (95\% Confidence Interval) & Hazard Ratio (95\% Confidence Interval)* \\
\hline Asian & 1.00 (reference) & $1.00($ reference) \\
\hline
\end{tabular}

${ }^{*}$ Hazard ratios adjusted for age, gender, BMI, diagnosis, MELD score at listing, presence of HCC, presence of HCV, presence of HBV, organ location and history of diabetes BMI: Body Mass Index; MELD: Model for End-Stage Liver Disease; HCC: Hepatocellular Carcinoma; HCV: Hepatitis C Virus; HBV: Hepatitis B Virus

Table 4: Cox proportional hazard regression results of patient survival among patients who received liver transplantation: Pre-Share 35 vs. Post-Share 35 time periods, 2012-2015. 
waiting list, the Share 35 policy significantly shortened their waiting time on list, increased the percentages of regional organs and improved their waiting list outcomes, as measured by death prior to transplantation or removal from the waiting list due to being too sick for transplantation. An important finding in this study was the lack of disparities in transplant rates between Asians and whites after accounting for other demographic, clinical, and geographic characteristics. This finding was comparable to preliminary results of recent studies after Share 35 policy took effect [4,7-9]. Therefore, the implementation of Share 35 policy, with its emphasis on reducing mortality on waiting list, though did not lead to improved access to liver transplantation for Asian patients so far but eliminated the previously observed disparities in waiting list.

However, compared to white candidates, Asian candidates still need to wait almost $50 \%$ more time before they received liver transplantation, regardless of Share 35 policy. Delayed in the access to liver transplantation were found likely to result in higher MELD scores, more advanced disease, greater disease-related morbidity, impaired access to quality pre-transplant care, and may be associated with worse post-transplantation outcomes $[5,12,13]$. Possible reasons behind the long waiting time included the partly shortage of eligible liver donors in the donor pool where the majority of donors are white race, as numerous studies have already highlighted the adverse impact of donor and recipient race mismatch on post-transplant outcomes [14-16].

Although we studied different population and time periods, our results were comparable to those preliminary analyses that still no significantly difference in the post-transplantation patient survival was observed between Asian and white patients when considering transplant center effect and other factors at one and half year outcome under the new policy. Continued investigation with longer followup would be necessary to assess the long-term impact of Share 35 policy, as Asian patients have long been considered to have outcomes superior to all other ethnic groups [5]. Particularly noteworthy was that the previous disparity- or transplantation survival-related studies have only stratified on Organ Procurement and Transplant Network (OPTN) regions and some even have not correctly adjusted for geographic or transplant center factors that may affect the receipt of liver transplantation $[4,17,18]$. There has been documented that the likelihood of receiving a liver transplantation varies in different parts of the country and is related to the local availability of deceased organ donors [19]. This study went beyond the previous ones that a carefully designed statistical marginal approach with a working independence assumption was incorporated so that each region or transplant center was treated as a cluster in all logistic and proportional hazard regression models to account for the impact of geographic variation and transplant center.

Moreover, an interesting finding was that the average BMI among Asian patients in this study demonstrated an increasing trend in the post-Share 35 era, though it was significantly lower than the white cohort. This is especially important for Asian populations since they had greater rates of central obesity and visceral deposition of fat and therefore at greater risk of metabolic syndrome and non-alcoholic fatty liver disease (NAFLD) compared to other ethnic groups with similar BMI $[20,21]$. This may further contribute to increased risk of nonalcoholic steatohepatitis (NASH) development and may result in an increasing number of patients impacting the liver transplantation waiting list [22].

This study has limitations inherent to the retrospective nature and lack of systematic data collection of the UNOS database. Racial and ethnicity data were self-reported, which was prone to misclassification bias. Second, the statistical models were limited by variables in the UNOS database. Socioeconomic factors such as education, median household income, health insurance status were not collected and these have been considered to be conceptually linked to a patient's choice of a transplant center as well as the access to liver transplantation [4,23-26]. In addition, genetic variations that contributed to lower survival rates in the post-transplantation setting were not available, either. Recipients with CYP3A5 polymorphism, which occurs in $10-40 \%$ of whites and $33 \%$ of Asians in the general population, require a higher dose of tacrolimus to achieve target trough levels for immunosuppressive therapies [27]. However, due to the size of the database, the analysis of the UNOS is so far the most possible and comprehensive analysis today.

\section{Conclusion}

In summary, this study was the first and largest to date reporting on the trends and outcomes of liver transplantation among Asian ethnicity residing in the United States under the Share 35 policy and it adds to the existing knowledge for other ethnic groups. We would agree that the liver allocation system is getting fairer than decades age but balancing the access to the scarce medical resources remains challenge to the entire transplant community including physicians, surgeons, and policy makers. Future researches with long-term follow-up time are recommended to continuously evaluate the effectiveness of the new policy.

\section{References}

1. Colby SL, Ortman JM (2015) Projections of the size and composition of the U.S. population: 2014 to 2060. Current Population Reports, pp: 25-1143.

2. Robbins AS, Daily MF, Aoki CA (2008) Decreasing disparity in live transplantation among white and Asian patients with hepatocellular carcinoma, California, 1998-2005. Cancer 113: 2173-2179.

3. Kemmer NM, Neff GW (2009) Liver transplantation tends and survival in the Asian population. Clinical and Translational Research 88: 392-394.

4. Mathur AK, Schaubel DE, Gong Q, Guidinger MK, Merion RM (2010) Racial and ethnic disparities in access to liver transplantation. Liver Transpl 16: 10331040

5. Kemmer N (2011) Ethnic disparities in liver transplantation. Gastroenterol Hapatol 7: 302-307.

6. Reid AE, Resnick M, Chang Y, Buerstatte N, Weissman JS (2004) Disparity in use of orthotopic liver transplantation among blacks and whites. Liver Transp 10: 834-841.

7. Massie AB, Chow EK, Wickliffe CE (2015) Early changes in liver distribution following implementation of Share 35. American Journal of Transplantation 15 659-667.

8. Annamalai A, Ayoub W, Sundaram V, Klein A (2015) First look: one year since inception of regional Share 35 policy. Transplantation Proceedings 47: 1585-1590.

9. Gentry SE, Chow EK, Whickliffe CE (2014) Impact of broader sharing on the transport time for deceased donor livers. Liver Transpl 20: 1237-1243.

10. http://www.unos.org/about/index.php.

11. Harper AM, Baker AS (1995) The UNOS OPTN waiting list: 1988-1995. Clin Transpl, pp: 69-84

12. Moylan CA, Brady CW, Johnson JL, Smith AD, Tuttle-Newhall JE, et al. (2008) Disparities in liver transplantation before and after introduction of the MELD score. JAMA 300: 2371-2378

13. Mathur AK, Sonnenday CJ, Merion RM (2009) Race and ethnicity in access to and outcomes of liver transplantation: A critical literature review. Am J Transplant 9: 2662-2668

14. http://www.organdonor.gov/dtcp/nationalsurveyorgandonation.pdf.

15. Layden JE, Cotler SJ, Grim SA, Fischer MJ, Lucey MR, et al. (2012) The impact of donor and recipient race on survival after hepatitis C-related liver transplantation. Transplantation 93: 444-449. 
Citation: Zhang Y (2017) Access to Liver Transplantation and Patient Survival among Asian Populations: Pre-Share 35 vs. Post-Share 35 . Health Care Current Reviews 5: 187. doi: 10.4172/2375-4273.1000187

Page 5 of 5

16. Norvell JP, Levitsky J (2013) Donor and recipient effects on graft and patient survival. Clinical Liver Disease 2: 152-155

17. Roberts JP, Dykstra DM, Goodrich NP, Rush SH, Merion RM, et al. (2006) Geographic differences in event rates by model for end-stage liver disease score. Am J Transplant 6: 2470-2475.

18. Trotter JF, Osgood MJ (2004) MELD scores of liver transplant recipients according to size of waiting list: impact of organ allocation and patient outcomes. JAMA 291: 1871-1874.

19. Zorzi D, Rastellini C, Freeman $\mathrm{DH}$, Elias G, Duchini A, et al. Increase in mortality rate of liver transplant candidates residing in specific geographic areas: analysis of UNOS data. Am J Transplant 12: 2188-2197.

20. Wong RJ, Ahmed A (2014) Obesity and non-alcoholic fatty liver disease: Disparate associations among Asian populations. World J Hepatol 2014; 6 : 263-273.

21. Farrell GC, Wong VM, Chitturi S (2013) NAFLD in Asia as common and important as in the West. Nat Rev Gastroenterol Hepatol 10: 307-318.
22. Charlton MR, Burns JM, Pederson RA, Watt KD, Heimbach JK, et al. (2011) Frequency and outcomes of liver transplantation for nonalcoholic steatohepatitis in the United States. Gastroenterology 141: 1249-1253.

23. Bryce CL, Angus DC, Arnold RM (2009) Socio-demographic differences in early access to liver transplantation services. Am H Transplant 9: 2092-2101.

24. Ananthakrishnan AN, Saeian K (2008) Racial differences in liver transplantation outcomes in the MELD era. Am J Gastroenterol 103: 901-910.

25. Yoo HY, Thuluvath PJ (2004) Outcome of liver transplantation in adult recipients: Influence of neighborhood income, education and insurance. Liver Transpl 10: 235-243.

26. Thammana RV, Knechtle SJ, Romero R (2014) Racial and socioeconomic disparities in pediatric and young adult liver transplant outcomes. Liver Transp 20: $100-115$.

27. Lamba JK, Lin YS, Schuetz EG, Thummel KE (2002) Genetic contribution to variable human CYP3A-mediated metabolism. Adv Drug Deliv Rev 54: 1271 1294. 